\title{
Use of oral miltefosine for cutaneous leishmaniasis in Canadian soldiers returning from Afghanistan
}

\author{
Yoav Keynan $M D^{1}$, Oscar E Larios $M D^{1}$, Marni C Wiseman $M^{2}$, \\ Marie Plourde $\mathrm{PhD}^{3}$, Marc Ouellette $\mathrm{PhD}^{3}$, Ethan Rubinstein $\mathrm{MD}^{1}$
}

Y Keynan, OE Larios, MC Wiseman, M Plourde, M Ouellette, E Rubinstein. Use of oral miltefosine for cutaneous leishmaniasis in Canadian soldiers returning from Afghanistan. Can J Infect Dis Med Microbiol 2008;19(6):394-396.

Old world cutaneous leishmaniasis (CL) is caused by Leishmania major and Leishmania tropica, and is endemic to several Asian and MiddleEastern countries where the rates of infection can be substantial. CL is one of the most common vector-transmitted parasitic infections in Afghanistan. Six cases of CL in Canadian soldiers returning from Afghanistan are reported in the present study. Their lesions did not improve with fluconazole therapy, and the organism demonstrated in vitro resistance. Oral miltefosine seemed effective.

\author{
La miltéfosine orale pour traiter une \\ leishmaniose cutanée chez des soldats \\ canadiens de retour d'Afghanistan
}

Key Words: Cutaneous leishmaniasis; Leishmaniasis; Phlebotomus

Cutaneous leishmaniasis (CL) is an important vector-borne disease encountered globally (1), with the potential to cause significant scarring. Leishmania species known to cause CL include Leishmania major, Leishmania tropica and Leishmania aethiopica, but CL can also be caused by species that cause visceral leishmaniasis. The parasite is transmitted through the bite of a diverse species of the female sandfly - Phlebotomus.

After an incubation period of approximately three to 12 weeks, CL begins as an erythematous papule that gradually develops into an ulcer. The lesion heals spontaneously over a period of six to 12 months, usually resulting in scar formation. $L$ tropica and L major are clinically indistinguishable; however, L tropica infection is described as a 'dry' noduloulcerative lesion that persists longer and is relatively resistant to treatment. It can also cause leishmaniasis recidivans (new lesions appear around a healed lesion) in approximately $5 \%$ of individuals (2).

The deployment of military personnel in Iraq, Kuwait and Afghanistan led to 522 parasitologically confirmed cases of CL reported by the United States Department of Defense between 2002 and 2004. Most of the cases were in soldiers deployed in Iraq, where $L$ major predominates (3). CL in Afghanistan is caused by $L$ major and $L$ tropica, with the most common vector being Phlebotomus sergenti. The two organisms causing CL differ in the spectrum of clinical diseases they cause, as well as in their response to therapy $(4,5)$. L tropica is the most common cause of $\mathrm{CL}$ in Afghanistan. It may have recrudescence at the site of a healed scar, and on rare occasions, L tropica may lead to a systemic infection, as previously reported in American soldiers during operation Desert Storm $(6,7)$.
The city of Kabul in Afghanistan is the world's largest focus of CL, with an estimated 67,500 to 200,000 new cases annually in a population of just over three million (approximate incidence of $2 \%$ to $5 \%$ ) (5). Cases of CL have also been reported in British, Dutch and German troops deployed to the city of Mazar-e Sharif (8).

The optimal treatment of 'old world' CL depends on the site of the lesion, the number of lesions and personal preferences. Paromomycin has been shown to be less effective in achieving complete cure of L tropica; fluconazole has variable success rates, depending on the species, but is cheap and easy to administer $(9,10)$. Local and systemic antimony therapy have shown superior results in studies from both Israel and Saudi Arabia (7,11). The efficacy of local warming achieved by application of a short-wave lamp has been demonstrated in a randomized controlled trial (12) conducted in Kabul. Oral miltefosine, an antitumour agent, has been used for treatment of visceral leishmaniasis in India and for mucocutaneous and CL in South America. The drug is contraindicated during pregnancy; concomitant oral contraceptives should be prescribed for women of child-bearing age (13-15).

\section{CASE PRESENTATIONS: SIX CASES OF CL ACQUIRED IN SOUTHERN AFGHANISTAN (TABLE 1)} Case 1

A 25-year-old Canadian Forces infantry male soldier presented with a nonhealing sore on the right fourth proximal phalanx. He had been deployed for six months in

${ }^{1}$ Departments of Medical Microbiology and Infectious Diseases; ${ }^{2}$ Section of Dermatology, Department of Medicine, University of Manitoba,

Winnipeg, Manitoba; ${ }^{3}$ Centre de Recherche en Infectiologie du Centre de Recherche du CHUL, Département de Microbiologie, Faculté de

Médecine, Université Laval, Laval, Quebec

Correspondence: Dr Ethan Rubinstein, Section of Infectious Diseases, University of Manitoba, Room 501, 730 William Avenue, Winnipeg,

Manitoba R3E OW3. Telephone 204-977-5681, e-mail erubius@yahoo.com

Received for publication May 21, 2008. Accepted August 1, 2008 
TABLE 1

Six cases of cutaneous leishmaniasis acquired by Canadian infantry soldiers in southern Afghanistan

\begin{tabular}{|c|c|c|c|c|c|}
\hline $\begin{array}{l}\text { Age, } \\
\text { years }\end{array}$ & $\begin{array}{l}\text { Duration of } \\
\text { stay in } \\
\text { Afghanistan }\end{array}$ & $\begin{array}{l}\text { Lesions } \\
\text { (n) }\end{array}$ & $\begin{array}{l}\text { Response to } \\
\text { fluconazole } \\
200 \mathrm{mg} / \mathrm{day} \\
\text { for six weeks }\end{array}$ & $\begin{array}{l}\text { Response to } \\
\text { miltefosine } \\
150 \mathrm{mg} / \text { day } \\
\text { for } 28 \text { days }\end{array}$ & $\begin{array}{l}\text { Other } \\
\text { treatment }\end{array}$ \\
\hline 25 & Six months & 1 & No & Not tried & $\begin{array}{l}\text { Stibogluco- } \\
\text { nate for } \\
28 \text { days }\end{array}$ \\
\hline 26 & Six months & 1 & No & Responded & \\
\hline 24 & Six months & 1 & No & $\begin{array}{l}\text { Discontinued, } \\
\text { abdominal } \\
\text { pain }\end{array}$ & Malarone* \\
\hline 24 & Six months & 3 & No & Responded & \\
\hline 24 & Six months & 2 & No & Responded & \\
\hline 24 & Six months & 1 & No & Responded & \\
\hline
\end{tabular}

${ }^{*}$ GlaxoSmithKline Inc, Canada

Afghanistan, in the city of Kandahãr. Before returning to Canada, he noted a lesion described as a painless 'pimple'. Over the course of three months, the lesion increased in size to $1 \mathrm{~cm} \times 2 \mathrm{~cm}$. It progressed further to a painful ulcer with serosanguineous discharge. He did not have accompanying fever, chills or other systemic symptoms, and was able to participate in all physical activities.

In Afghanistan, he initially received two courses of oral antibiotics without clinical improvement. The lesion at this point was painless, but bleeding with minor trauma was the chief complaint. Subsequently, a working diagnosis of pyoderma gangrenosum was entertained, and he was started on oral steroid treatment with further clinical deterioration. A skin biopsy revealed a hyperplastic epidermis with parakeratosis and focal ulceration. There were also structures seen that were suggestive of amastigote forms of Leishmania.

At this point, the patient was referred to an infectious disease specialist; by that time, the lesion had progressed further, measuring $3 \mathrm{~cm} \times 2 \mathrm{~cm}$. It appeared ulcerative with raised and erythematous borders (Figure 1). He had normal baseline blood work and normal computed tomography scans of the abdomen and pelvis. He was treated for six weeks with oral fluconazole with no improvement. Polymerase chain reaction analysis (performed at the National Reference Centre for Parasitology McGill University Centre for Tropical Diseases Montreal General Hospital Research Institute, Montreal, Quebec) of a biopsy specimen from the lesion revealed $L$ tropica. He was then treated with intravenous stibogluconate for 28 days with subsequent healing.

\section{Case 2}

A 26-year-old Canadian Forces infantry female soldier deployed in southern Afghanistan between August 2006 and February 2007 reported a penny-sized lesion on her upper left arm that was first noted in early 2007. She received a course of fluconazole without significant change to the lesion. The ulcer healed over the ensuing six months, with a small area of scarring without further therapy. In the beginning of 2008, the skin ulceration reappeared and biopsy confirmed the presence of amastigotes; polymerase chain reaction analysis of a biopsy specimen revealed $L$ tropica. The patient received miltefosine along with oral contraceptives.

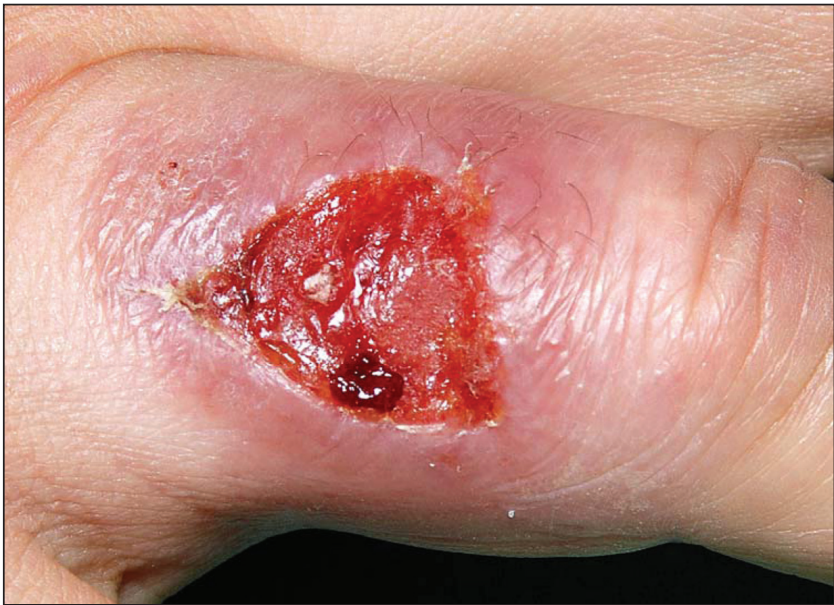

Figure 1) Case 1: Ulcer on the right fourth proximal phalanx surrounded by mild erythema and swelling

\section{Case 3}

A 24-year-old Canadian Forces infantry male soldier deployed in southern Afghanistan between August 2006 and February 2007 presented with a lesion on the lower lip. The lesion appeared in December 2006. He received a course of fluconazole with no apparent benefit. On returning to Canada, he received Malarone (GlaxoSmithKline Inc, Canada) for malaria prophylaxis (because of traveling to Central Africa), and reported contraction of the lesion. A biopsy was consistent with leishmaniasis. When seen in July 2007, a pea-sized palpable lesion on the lower lip was noted. The patient received miltefosine, but discontinued therapy after one week because of abdominal pain and loose stools. Because the lesion contracted, no further therapy was given.

\section{Case 4}

A 24-year-old Canadian Forces infantry male soldier deployed in southern Afghanistan between August 2006 and February 2007 observed a raised lesion on his lower abdomen in late 2006. Another lesion appeared on his left knee, followed by appearance of a third lesion, $2.6 \mathrm{~cm}$ in diameter, on the right elbow. A skin biopsy revealed granulomatous inflammation, and amastigotes were observed. Fluconazole did not cure the lesions, but they regressed after a four-week course of miltefosine, leaving typical scarring.

\section{Case 5}

A 24-year-old Canadian Forces infantry male soldier deployed in southern Afghanistan between August 2006 and February 2007 presented with lesions on the left side of his neck and upper back. Biopsy demonstrated granulomatous inflammation, and no amastigotes were seen. No response to a five-week course of fluconazole was noted. Therapy with miltefosine resulted in contraction and cure of both lesions.

\section{Case 6}

A 24-year-old Canadian Forces infantry male soldier deployed in southern Afghanistan between August 2006 and February 2007 first noted a $1.5 \mathrm{~cm}$ raised papular lesion on his right cheek in early 2007. A skin biopsy confirmed the diagnosis of CL. A course of fluconazole did not alter the lesion's size, and a course of miltefosine was prescribed, resulting in contraction and cure of the lesion. 


\section{DISCUSSION}

Since 1991, deployment of military forces in Asia and the Middle East has led to reports of CL in deployed personnel. Although the disease is nonfatal, it can lead to substantial scarring and disfigurement.

We report the first series of cases in Canadian soldiers deployed in the endemic leishmaniasis region of Afghanistan. The species found in these soldiers was $L$ tropica (confirmed in two of the six cases), which is known to be associated with a longer disease course, greater tendency for recurrence (as evident in patient 2) and resistance to several agents, but rarely leads to systemic disease. Within the Leishmania genus, unique strains are thought to be present in different parts of the genus' geographical distribution range, with potentially divergent susceptibilities $(7,16)$.

Pentavalent antimonials administered intralesionally or systemically are commonly used, but limited by toxicity and low compliance, as well as by the emergence of resistance (16). The optimal management of $L$ tropica-infected cases is not well defined, with studies from Turkey (10) and Israel (7) documenting lower response rates to fluconazole. The decrease in the size of the lesion in one of the patients (case 3), while he was receiving Malarone, could represent a response of the organism, but may be explained by the natural course of the infection. Further study of this oral agent for CL and potential prophylaxis may be warranted. The present case series documents failure to respond to fluconazole, a commonly used, well-tolerated oral agent for treatment of CL. Although antiparasitic susceptibility testing has not been definitively standardized, the organism was resistant to fluconazole in vitro, using a 96-well plate for antifungal susceptibility, as well as a novel luciferase tagging method (performed at the Centre de Recherche en Infectiologie du Centre de Recherche du

\section{REFERENCES}

1. World Health Organization. The world health report: Changing history. Geneva: World Health Organization, 2004:1-96. $<$ http://www.who.int/whr/2004/en/report04_en.pdf> (Version current at July 30, 2007).

2. Murray HW, Berman JD, Davies CR, Saravia NG. Advances in leishmaniasis. Lancet 2005;366:1561-77.

3. Center for Disease Control and Prevention (CDC). Update: Cutaneous leishmaniasis in U.S. military personnel - Southwest/ Central Asia, 2002-2004. MMWR Morb Mortal Wkly Rep 2004;53:264-5.

4. Aronson NE, Sanders JW, Moran KA. In harm's way: Infections in deployed American military forces. Clin Infect Dis 2006;43:1045-51.

5. Reithinger R, Coleman PG. Treating cutaneous leishmaniasis patients in Kabul, Afghanistan: Cost-effectiveness of an operational program in a complex emergency setting. BMC Infect Dis 2007;7:3.

6. Magill AJ, Grogl M, Gasser RA, Sun W, Oster CN. Visceral infection caused by Leishmania tropica in veterans of Operation Desert Storm. N Engl J Med 1993;328:1383-7.

7. Shani-Adir A, Kamil S, Rozenman D, et al. Leishmania tropica in northern Israel: A clinical overview of an emerging focus. J Am Acad Dermatol 2005;53:810-5.

8. Faulde MK, Heyl G, Amirih ML. Zoonotic cutaneous leishmaniasis, Afghanistan. Emerg Infect Dis 2006;12:1623-4.

9. Herwaldt BL. Leishmanisis. Lancet 1999;354:1191-9.
CHUL and Département de Microbiologie, Faculté de Médecine, Université Laval, Laval, Quebec). Although there is documented efficacy of miltefosine against visceral leishmania in India, and mucocutaneous and CL from South America, few reports on its use for 'old world' CL are available. Reithinger et al (17) and Soto and Soto (18) reported a $63 \%$ response rate of $L$ tropica to miltefosine in Afghanistan. Four of the patients responded to miltefosine, to which in vitro susceptibility was documented. One patient suffered gastrointestinal discomfort and withdrew therapy. Thus, miltefosine provides an orally available treatment option that may prove invaluable for the treatment of CL contracted in southern Afghanistan.

The present case series highlights the salient features of CL caused by $L$ tropica, namely chronic skin ulceration and the propensity for recurrences. Physicians should consider CL in the differential diagnosis of ulcerative lesions in patients returning from endemic areas. The important feature of the specific organism isolated from these individuals is the failure to respond to fluconazole treatment causing prolonged skin ulceration. Although failure with fluconazole therapy is not unusual, the ease of administration and the well-studied safety profile make it a frequently used agent in this nonlifethreatening form of leishmaniasis. The observation of successful treatment with miltefosine may provide an alternative oral antiparasitic agent. Finally, the use of susceptibility testing to predict the outcome of treatment for this geographically diverse parasite should allow tailoring of an appropriate treatment strategy.

ACKNOWLEDGEMENTS: Marc Ouellette is a Burroughs Wellcome Fund Scholar in molecular parasitology and a Canada Research Chair in antimicrobial resistance.
10. Ozgoztasi O, Baydar I. A randomized clinical trial of topical paromomycin versus oral ketoconazole for treating cutaneous leishmaniasis in Turkey. Int J Dermatol 1997;36:61-3.

11. Alkhawajah AM, Larbi E, al-Gindan Y, Abahussein A, Jain S. Treatment of cutaneous leishmaniasis with antimony: Intra-muscular versus intralesional administration. Ann Trop Med Parasitol 1997;91:899-905.

12. Reithinger R, Mohsen M, Wahid M, et al. Efficacy of thermotherapy to treat cutaneous leishmaniasis caused by Leishmania tropica in Kabul, Afghanistan: A randomized, controlled trial. Clin Infect Dis 2005;40:1148-55.

13. Bhattacharya SK, Jha TK, Sundar S, et al. Efficacy and tolerability of miltefosine for childhood visceral leishmaniasis in India. Clin Infect Dis 2004:38:217-21.

14. Sundar S, Jha TK, Thakur CP, et al. Oral miltefosine for Indian leishmaniasis. N Engl J Med 2002;347:1739-46.

15. Soto J, Arana BA, Toledo J, et al. Miltefosine for new world cutaneous leishmaniasis. Clin Infect Dis 2004;38:1266-72.

16. Hadighi R, Boucher P, Khamesipour A, et al. Glucantime-resistant Leishmania tropica isolated from Iranian patients with cutaneous leishmaniasis are sensitive to alternative antileishmania drugs. Parasitol Res 2007;101:1319-22.

17. Reithinger R, Leslie T, Mohsen M, et al. A randomized controlled trial to test the efficacy of miltefosine against Leishmania tropica in Kabul, Afghanistan. Third World Congress on Leishmaniasis, 2005.

18. Soto J, Soto P. Oral miltefosine to treat leishmaniasis. Biomedica 2006;26(Suppl 1):207-17. 


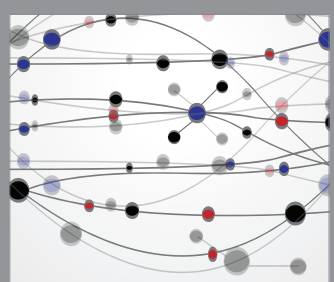

The Scientific World Journal
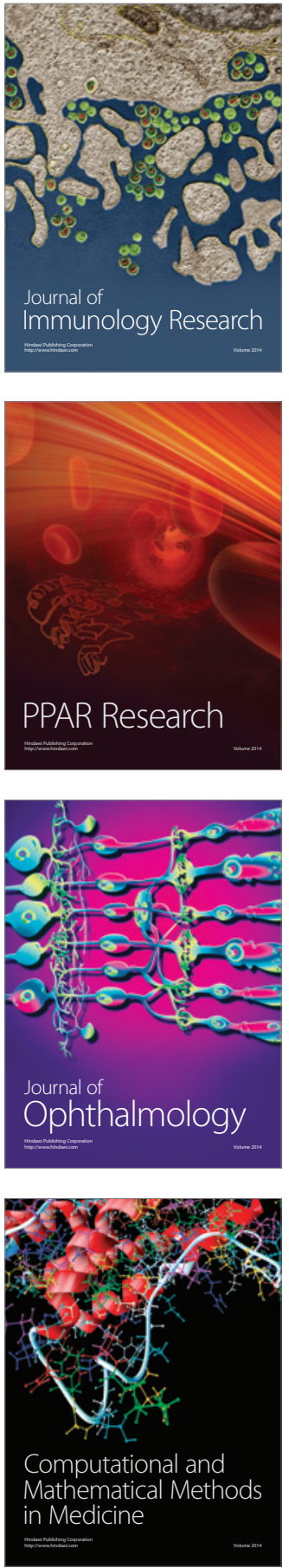

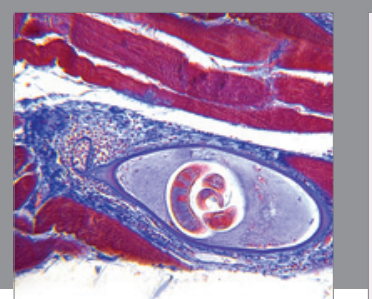

Gastroenterology Research and Practice

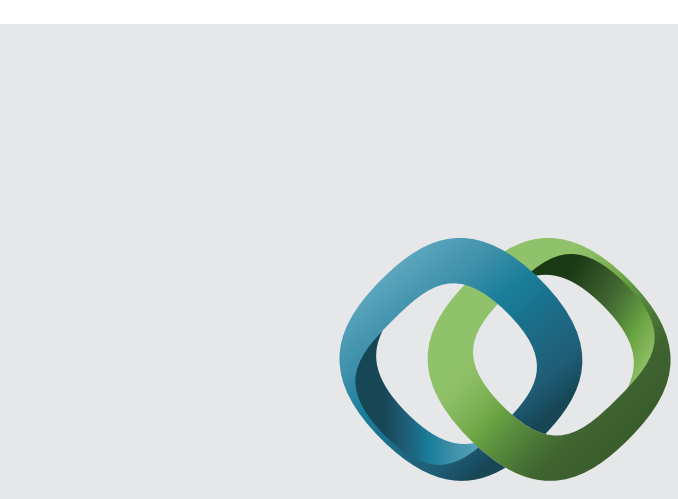

\section{Hindawi}

Submit your manuscripts at

http://www.hindawi.com
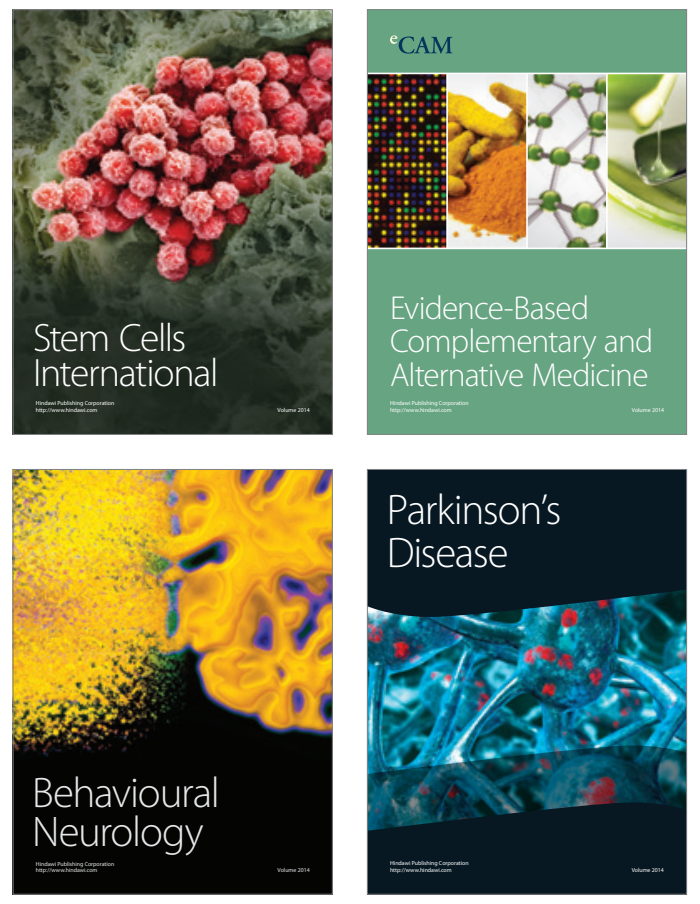
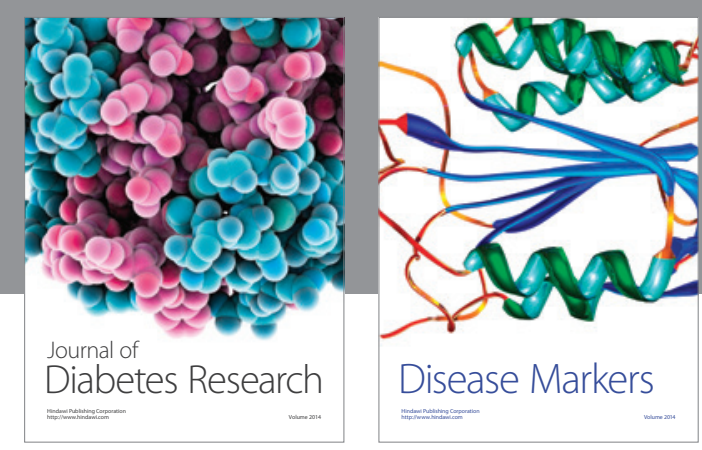

Disease Markers
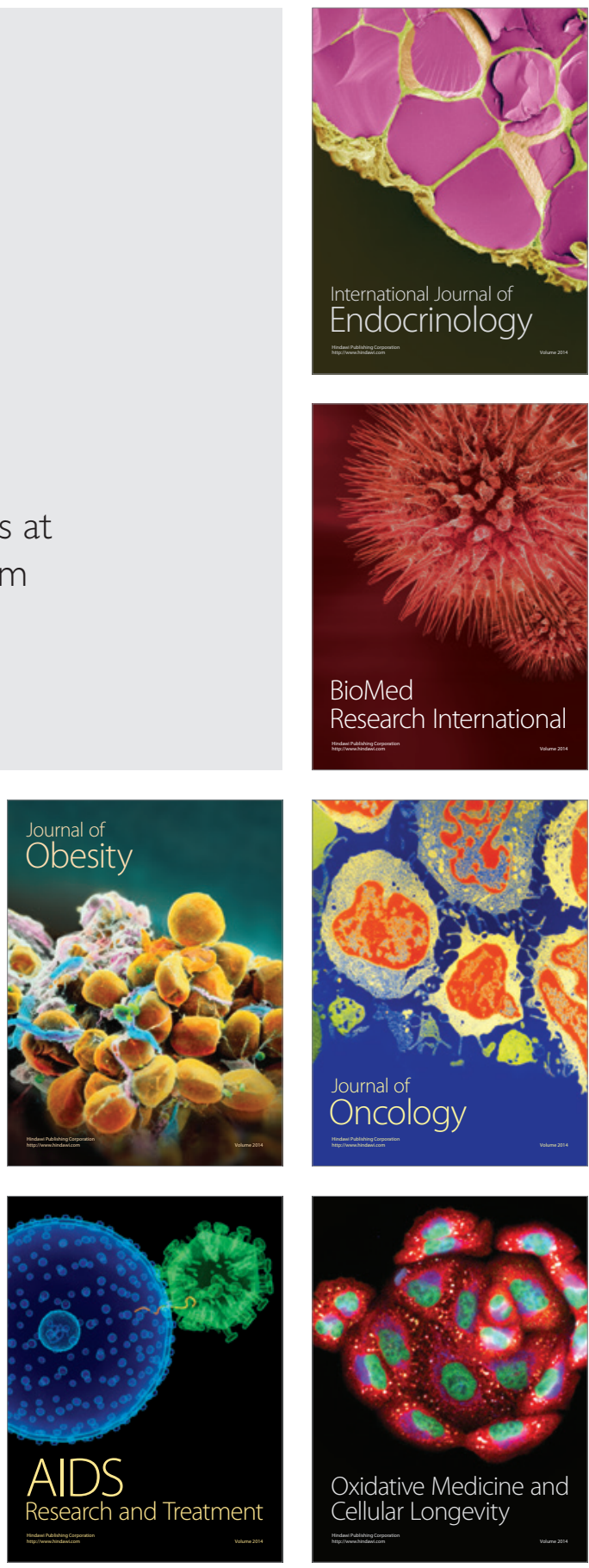